\title{
Don't Forget the Gravy! Are Bonuses Just Added on Top of Salaries?
}

\author{
Colin P. Green \\ Economics Department, Lancaster University, Lancaster UK LA1 4YT \\ Ph, +44 1524594667 e-mail. c.p.green@lancaster.ac.uk
}

John S. Heywood

Economics Department, Bolton Hall, University of Wisconsin-Milwaukee

Milwaukee, WI 53211 USA

Ph (414) 229-4437/431 e-mail Heywood@uwm.edu

\begin{abstract}
The press often depicts bonuses as extra payments to the already well compensated and calls for reform. Yet, these calls typically ignore the efficiency argument that bonuses are potentially risky performance pay that substitute for salary compensation. This paper uses representative UK data to estimate that bonuses appear not to substitute for salary in crosssectional estimates. Yet, when controlling for time invariant characteristics in panel data, bonuses emerge as partial substitutes. Each pound of bonus comes at a cost of 40 pence in other earnings. The degree of substitution is far larger at the bottom of the earnings distribution and far smaller at the top of the earnings distribution where, indeed, bonuses look more like gravy.
\end{abstract}

Keywords: Bonus Payments, Performance Pay, Complements

Acknowledgement: The authors thank Antonio Galvao and seminar participants at UWM, the Scottish Economic Society and at the "Beyond Wages" conference at the British Academy for helpful comments. We are also grateful to the comments of the editor, Steven Raphael, and two anonymous referees on a previous version of this paper. Appreciation is also expressed to the UK Data Archive that made the BHPS available. 


\section{INTRODUCTION}

The payment of bonuses as part of managerial and executive compensation attracts continued public controversy. The media highlight the size of bonuses paid at financial institutions, often with the application of pejorative terms such as 'bonus culture' that suggest the payment of something for nothing. ${ }^{1}$ Indeed, the depth of public feeling regarding bonuses has led to pronouncements by both the US president and the UK prime minister on the need to restrain these "inequitable payments" and proposed legislations to cap bank bonuses in the EU. The public perception of something for nothing seems at odds with the basic theory that bonuses, like other forms of performance pay, represent a means to mitigate agency problems in labour contracts. Payment contingent on worker performance stands in lieu of some portion of an otherwise riskless (or at least less risky) salary payment and serves to increase firm profitability, worker utility or both. In fact, the presumption that high performance bonuses substitute for salaries provides the basis for the resistance by both the UK and US financial sector to cap or reduce bonus payments. Advocates for the sector explicitly claim that reducing bonuses will lead to either a necessary compensating increase in salary payments or a loss of talent within the sector.

The basic notion that performance pay elicits additional effort and is associated with increased earnings stands as well engrained in the economics of personnel (Brown 1992, Lazear 2000; Parent 1999; Shearer 2004). Yet, the combination of the disutility from greater effort and risk has left in doubt the extent to which the higher pay generates higher worker utility from performance pay (Cornelissen et al. 2011; Green and Heywood 2008). At least part of the answer of whether or not workers benefit from performance pay revolves around the critical issue at the heart of the public debate, the extent to which performance pay substitutes for fixed time rates. As we will detail, previous empirical results often fail to find any substitution showing that higher performance payments tend to be associated with higher fixed time rates. If correct, the performance pay in these studies would represent "gravy" simply poured on top of fixed rates. We provide a unique study focused on bonus payments.

In contributing to this issue, we emphasize that none of the previous studies directly examining substitutability control for worker fixed effects despite routine evidence that performance pay causes worker sorting on characteristics such as ability. Using panel data from the UK, we confirm the importance of accounting for worker fixed effects. We present pooled cross-sectional evidence suggesting that bonuses are entirely gravy and a complement 
to other earnings. Yet, when controlling for worker fixed effects, and the associated sorting, we show that bonuses are partial substitutes for other earnings. In particular, we find that around 60 pence of every pound of bonuses is translated into increased earnings. Put differently, each pound of bonus costs 40 pence in lost other earnings. Moreover, when we explore the distributional aspects of this correlation through quantile regression, the extent of substitution is far larger at the bottom of the earnings distribution. While we provide some speculation on this distributional aspect, our primary contribution is a unique focus on bonus payments, an improvement on previous studies that attempt to measure the degree of substitution between performance pay and time rates and our ability to find such substitution.

In what follows, the next section provides further motivation for our examination and reviews previous empirical studies. The third section provides our data and methodology. Section four presents the critical results and a series of robustness checks as well as our quantile regression estimates. A fifth section concludes.

\section{MOTIVATION AND THEORETICAL BACKGROUND}

Perhaps the most dramatic example of substitution comes from the history of concern over ratchet effects in which fixed rates are replaced by piece rates which are then lowered when workers respond with greater productivity (see Carmichael and MacLeod 2000; Freeman and Kleiner 2005; Gibbons 1987). Yet, even apart of these dynamic concerns, the two basic static models of performance pay each predict partial substitution. The principal-agent and sorting models do differ in the extent to which workers' earnings will increase as a result of performance pay (Cornelissen et al. 2011). The former assumes a reservation utility constraint and argues total earnings increase only enough to compensate for the increased cost of effort and for assuming additional risk. While optimal risk sharing may prohibit fixed earnings from being zero, it is also clear that the addition of a productivity contingent pay on top of fixed earnings that remain at their no risk, minimal effort reservation level can only improve worker utility and so violate the utility constraint. In short, no firm should have an incentive to provide such a contract and so the advent of performance contingent pay substitutes at least partially for fixed earnings.

The second type of model argues that workers capture individual rents and the firm faces a zero profit constraint. The key feature of these models is that the reliance on performance pay causes sorting in which those with greater ability (less disutility from effort) 
choose the performance pay scheme while the less able sort into the fixed pay scheme. This sorting on ability would simply not happen if the performance pay sector guaranteed the same fixed pay and simply added performance pay on top. Thus, while capturing rents may cause total earnings to go up more in the performance pay sector than in the principal-agent model, it would still predict partial substitution. The very point of the performance pay is to reduce the fixed salary component in order to make earnings depend, if imperfectly, on worker productivity. Certainly, neither of the basic models implies that moving from fixed earnings to performance pay causes the fixed earnings to increase while the performance pay is simply added on top. Instead, the two forms of pay should be partial substitutes.

At first glance such a discussion may seem quite removed from the popular discussion of bonus payments. Yet, to the contrary, it sits implicitly at the heart of the arguments given by those opposing the restriction of bonus payments. First, as noted in the introduction, they argue that any reduction in bonus payments will lead to a necessary positive adjustment to the salary component of pay (as suggested by the principal-agent constraint). Second, they claim that any reduction in bonus payments (PRP) will lead to a loss of talent in industries currently paying bonuses (as suggested by the sorting model).

The prediction from both models is critical for empirical work as the, admittedly modest, previous empirical literature often fails to confirm any substitution at all. It finds that greater performance pay is, indeed, often associated with larger fixed pay. Among those who do find partial substitution, Kaufman (1998) uses a survey of US firms implementing gain sharing to follow earnings before and after the plans are implemented. He estimates that gain sharing is not "pure gravy" as other compensation falls but not by as much as the gain sharing payment. Barkume (2004) has more detailed data from the US Employment Cost Index on specific jobs (but not workers and their characteristics). He finds that incentive pay (largely piece rates) increases total employer costs for employee compensation but it is associated with reductions in other forms of compensation suggesting partial substitution. Importantly, both of these papers focus on types of performance pay typically oriented to line production workers. On the other hand, a series of examinations of profit sharing payments fail to find evidence of substitution (Cahuc and Dormont 1997 for France; Hart and Huebler 1991 for Germany; Wadhwani and Wall 1990 for the UK;). Indeed, the studies of both France and Germany present evidence that profit shares are positively associated with base wages suggesting complementarity. Mitchell et al. (1990) examine bonus payments showing that they are also positively associated not only with total compensation but with base wages 
suggesting, again, not substitution but complementarity. Thus, previous evidence presents a surprising number of positive associations between performance pay and base wages when neither of the basic static models would predict such a result. ${ }^{2}$

In addition to the failures to confirm substitution cited above, other literatures might cast doubt on the basic implications of principal-agent and sorting models. The separation between ownership and control may allow managers substantial latitude in determining both their own contracts and those of their employees. Bertrand and Mullanaithan (2001) and Albanesi and Olivetti (2008) present evidence that CEOs `skim’ rents from firms, especially in favourable conditions where they are less likely to be detected. Indeed, linking these skimmed rents with "performance" may be crucial in reducing their likelihood of detection as it is often difficult to accurately determine the influence of the CEO on performance. Empirical evidence accords with this showing that more severe agency problems are associated with unusually high performance payments such as options and other incentives (Bebchuk et al. 2002; Brick et al. 2012). This can be relevant to workers beyond the upper management if managers with high powered incentives tend to devise higher powered incentives for their workers (See Heywood et al. 2006). Kruger (1991) confirms that the earnings of line workers are higher when owners do not manage. Similarly, Groshen and Kruger (1990) show that when earnings of managers are higher so are those of other occupations even holding constant, as best as possible, job content and supervision. Thus, it is not inconceivable that the separation of ownership from control could allow both management and key workers to capture bonuses added on to large fixed compensation as part of portraying a performance oriented workplace to owners with imperfect information. ${ }^{3}$

Alternatively, bonuses may simply not be linked intimately to productivity and performance. In this view calling something a bonus in a survey or even within a firm's compensation scheme does not make it "performance pay" of the sort in the traditional models. Critically, there may be large elements of subjectivity in the determination of bonuses (MacLeod 2003). This subjectivity increases the latitude for managers who set bonuses. As a consequence, managers may follow objective functions other than simple rent skimming. Friebel and Raith (2004) describe a hierarchy in which supervisors at each level reward unproductive subordinates as a way of protecting themselves. ${ }^{4}$ Heywood (1991) presents a model in which managers "overpay" workers to reduce managerial effort associated with monitoring and job turnover. In addition, performance pay has been 
associated with greater racial earnings gaps (Heywood and Parent 2012). To the extent that bonuses reflect industrial politics, effort avoidance or attempts to discriminate they need not be linked to productivity and there becomes far less reason to think they necessarily substitute for fixed salary.

Indeed, theorists have explicitly questioned the traditional models. Zaharieva (2010) constructs a model that relies on heterogeneous jobs, incomplete information and equilibrium job search to introduce frictions that can explain the "stylized fact" of complementarity. Yet, before abandoning the more straightforward principal-agent and sorting models, we think the estimation should be revisited.

The presence of bonuses associated with profit sharing complicates the bonus measure used in our empirical estimates (although as reported in Table 1 of Green and Heywood (2011) they likely represent a small share of the total number of bonuses). Yet, even with profit sharing one might anticipate partial substitution. The Weitzman (1984) view that profit sharing lowers the marginal cost of labor requires that bonuses cannot simply be added on top of regular wages. If they were, the marginal cost of labor under profit sharing would not decrease below that of fixed wages during negative demand shocks and the employment effects associated with profit sharing would not be observed (Azfar and Danninger 2001; Green and Heywood 2011). On the other hand, Hart and Huebler (1991) emphasize that profit sharing may be a rent sharing tool oriented toward those with large specific human capital investments or even represent an efficiency wage. In these cases, complementarity might be more likely.

Crucially, findings that bonuses are complements could spuriously result from more productive workers sorting into performance pay jobs (including profit sharing jobs) and the inability to control for this in typical cross-section results. Indeed, none of the previous empirical examinations described above has exploited comprehensive individual panel data to construct tests of substitution. They use either firm level data or individual level data in relatively small cross-sections. This is critical as worker sorting on the basis of innate productivity is a well-known feature of the adoption of performance pay schemes (Lazear 2000). Failure to control for this is likely to lead to upwardly biased estimates of the relationship between salary and bonus payments as higher innate productivity is likely to positively influence both salary and bonus amounts. Panel data, and the ability to difference out innate productivity, is clearly advantageous in this setting. 
Previous research demonstrates that bonus payments are highly concentrated in the upper levels of the income distribution (Bell and Van Reenen 2010, 2013). While the size of bonuses for financial service workers garners substantial press attention, Lemieux et al. (2009) demonstrate that the growing incidence of performance pay in the US is associated with a large share of the growth in earnings inequality over the 1980s and 1990s and virtually all of the growth of earnings inequality in the upper quintile of the distribution. Our UK examination is timely in light of OECD research that earnings inequality is growing more quickly in the UK than in any other developed country (OECD 2011), and the evidence that this growth is uniquely tied to the financial services industry with its use of performance bonuses (Stewart 2011). Part of evaluating this trend, and perhaps an even more pointed equity examination, is determining the extent to which performance pay and other compensation substitute across the earnings distribution. The examination is not one of the extent to which bonuses are associated with inequality but rather of the extent to which bonuses appear to be part of a reward structure in which pay is at risk because fixed salaries are lower.

\section{DATA AND EMPIRICAL APPROACH}

The data we use are drawn from the British Household Panel Survey (BHPS). The BHPS is a nationally representative longitudinal sample that annually interviews approximately 10,000 individuals from roughly 5,500 households. We use the 1997 to 2008 period as prior to 1997 information on bonus amounts was simply not collected. We also limit our sample to male heads of households who were private sector employees.

The BHPS contains a range of information on earnings. We follow Bell and Van Reenen (2010) focusing on the measure of annual labour income, which along with all other earnings we deflate to 2005 pounds. This derived variable generated by the BHPS staff is constructed from weekly and monthly wages accounting for job changes and other potential variation in earnings. ${ }^{5}$ In addition to this derived annual earnings measure, respondents are asked to report whether "in the last 12 months have you received any bonuses such as a Christmas or quarterly bonus, profit-related pay or profit sharing bonus, or an occasional commission? [this excludes overtime payments]". If they answer yes, they are then asked for the amount of the bonus payment. Bell and Van Reenen (2010) demonstrate that these two figures, annual labour income and the additional bonus payment, are generally comparable to 
those reported in the UK ASHE data that are based on verified payment details. ${ }^{6}$ Additionally, workers are asked “Does your pay include performance-related pay?”, There are no pound amounts associated with question and we presume that it includes piece rates, commissions and performance increments among other things. As workers with bonuses may also receive such performance pay, or may even identify their bonus as performance pay, we control for such receipt.

\section{INSERT TABLE 1}

While we observe bonus amounts we do not observe when workers are subject to a bonus scheme but fail to meet the requirements for receiving a bonus in a given year. To examine this, we follow the method outlined in Lemieux et al. (2009) to identify "bonus jobs." In this method job matches which at any point paid a bonus are classified as bonus scheme jobs for all periods. Again, we demonstrate the robustness of the key results to this variation in the empirical section.

\section{INSERT FIGURE 1}

Table 1 presents key descriptive statistics divided by bonus receipt. Note that those receiving bonuses are more likely to receive other types of performance pay and that their annual labor income is substantially larger. This difference in means is not, by itself, surprising as those receiving bonus payments might be expected to be those with higher earnings capacity. The size of the average bonus among recipients is $£ 3,180$. All of these figures have been averaged across years but deflated by the consumer price index to a base year of 2005. Figure 1 shows that the real value of bonuses among recipients has increased substantially over the decade we examine. It reaches a high of £5,400 in 2007, but declines substantially the next year coinciding with the financial crisis. Figure 2 confirms that each year the annual labour income is larger for those that receive bonuses than for those who do not. As our empirical strategy relies heavily on worker fixed effects Table A1 presents information on the amount of within worker variation in income and bonus payment amounts, along with information on movements into and out of bonus receipt and the number of individuals who never receive bonuses and hence do not contribute to our main estimates. These reveal a substantial amount of within variation in both income and annual bonuses, moreover there are many observations of moving in and out of receipt (although note our fixed effects models are also identified by the changes in bonus amount), and $41 \%$ of individuals in our sample never receive a bonus. 


\section{INSERT FIGURE 2}

Bonus amount as a share of derived annual earnings shows the anticipated variation across the earnings distribution. As Figure 3a shows, the bonus share generally increases with earnings. It shoots up dramatically in the top five percent of the distribution. Figure $3 \mathrm{~b}$ concentrates on the upper decile showing that the share reaches its maximum in the single highest percentile in the distribution. In both cases we show this information for those in bonus receipt only. Approximately twenty percent of all earnings in the top five percent are in the form of bonuses and this share increases to more than twenty five percent at the top percentage point. This pattern suggests the importance of distributional considerations when estimating the extent of substitution and will motivate one vein of our empirical testing.

\section{INSERT FIGURE 3A, 3B}

We present a series of estimates that seek to examine the extent of substitution, with an emphasis on trying to eliminate any bias due to sorting of workers by ability. As a preliminary step our initial test merely examines if those receiving bonuses have higher annual earnings. We estimate the following equation:

$$
w_{i t}=\beta_{0}+\beta_{1} \text { Bonus }_{i t}+\beta_{2} P R P_{i t}+\gamma X_{i t}+\varepsilon_{i t}
$$

Where $w$ is annual labour income earned by individual $i$ in year $t$, Bonus indicates that they received a bonus (of any size) in that year, $P R P$ indicates other performance related pay receipt and $X$ is a vector of controls including age, union membership, temporary contract, firm size along with year, region, hours of work, industry and occupational dummies.

We extend this estimate using the information on the amount of bonus receipt available in the BHPS. We estimate:

$$
w_{i t}=\alpha_{0}+\alpha_{1} \text { BonusAmount }_{i t}+\alpha_{2} P R P_{i t}+\gamma X_{i t}+\epsilon_{i t}
$$

where BonusAmount is the pound value of the annual bonuses. Complete substitution implies that an additional pound of bonus will be reflected in no increase in annual earnings $\left(\alpha_{1}=\right.$ 0). Partial substitution implies that an additional pound of bonus will cause less than a pound increase in annual earnings $\left(0<\alpha_{1}<1\right)$. A pure gravy result would indicate total annual earnings increasing by at least the amount of the bonus $\left(\alpha_{1} \geq 1\right)$. Thus, to aid in interpreting the pound to pound relationship between bonus amounts and annual labour income, we estimate this and subsequent variations in linear specifications. We do provide variations that 
include a variable measuring the squared amount of bonus, to examine for non-linearity in the relationship between bonuses and annual labour income.

A number of empirical challenges exist in properly identifying $\alpha_{1}$. A fundamental difficulty not dealt with in previous empirical work is that unobserved worker productivity (ability) influences both bonus payment and wages. Thus, unmeasured ability might bias the coefficients toward complementarity as ability would be anticipated to simultaneously influence multiple dimensions of compensation. More specifically, it is well established that the presence of performance pay schemes leads to ability sorting across jobs in which the more able sort into such schemes (Curme and Stefanec 2007; Lazear 2000). Our main approach will control for worker specific fixed effects which remove first order bias in the estimates of $\alpha_{1}$ and $\beta_{1}$ due to time invariant worker characteristics. While attractive, this approach restricts the identification of our key parameters to those who we observe both with and without receipt or those for whom we observe some variation in the bonus payment amount. In the results section we spend considerable time examining the stability of the FE estimates and the sources of identification.

The concentration of bonus payments at the top of the earnings distribution leads to concerns regarding the role of bonus receipt in generating inequality (Bell and Van Reenen, 2010). Yet, this concern may be more or less pronounced depending on how the relationship between bonus payments and salary varies across the wage distribution. Thus, if one found that the high bonuses come at the cost of reduced salaries, the concern in the popular press that these bonuses are unjustified (represent rents) may be over-stated. We seek to examine this by estimating quantile regression analogues of (2) above, where for each quantile $\tau$ :

$$
Q_{\tau}\left(w_{i t}\right)=\alpha_{\tau 0}+\alpha_{\tau 1} \text { BonusAmount }_{i t}+\alpha_{\tau 2} P R P_{i t}+\gamma_{\tau} X_{i t}+\varepsilon_{\tau i t}
$$

Again, the key parameters of interest will suffer from ability bias in simple crosssectional estimates. A larger, more positive, relationship between bonus payment and salaries at higher salaries may just reflect the sorting of talent towards highly paid jobs. Fixed effect estimation again seems the most natural approach to addressing this. However, this is complicated in the quantile regression setting. One analogue to the fixed effects approach in linear regression is to include a worker specific shift for each individual for every $\tau$ th quantile. This might be termed a conditional (on the quantile) fixed effects quantile 
regression model. However, as discussed by Koenker (2004) including this type of this $\tau$ dependent distributional worker effect is difficult in practice in a setting such as ours where there a large number of cross-sectional units but the number of time observations per unit is not so large. Instead he suggests the inclusion of a single individual specific effect across the $\tau$ quantiles.

To do this requires the joint estimation of all $\tau$ quantile regressions simultaneously. This is termed an unconditional fixed effects quantile regression and takes the form:

$$
Q_{\tau}\left(w_{i t}\right)=\alpha_{i}+\alpha_{\tau 0}+\alpha_{\tau 1} \text { Bonus }_{i t}+\alpha_{\tau 2} P R P_{i t}+\gamma_{\tau} X_{i t}+\varepsilon_{\tau i t}
$$

A key aspect of this approach is that the individual fixed effects shift the conditional quantiles, but do not vary by quantile (Koenker, 2004). We estimate this using the rqpd package in the statistical program R. We pursue this estimation as part of examining the distribution aspects of bonus receipt while accounting for individual fixed effects.

We note that a log-log elasticity specification would be difficult to interpret in our quantile regression framework. The majority of bonus amounts are zero leading to infinite percentage increases when a bonus is received. Moreover, the share of income provided by bonuses increases dramatically across the distribution resulting in a distribution of elasticities even when $\alpha_{\tau 0}$ does not vary across the quantiles. Nonetheless, as a check of non-linearity, we will again include the square of the bonus amount as a robustness check.

\section{RESULTS}

Table 2 presents estimates of the association between bonus receipt and annual earnings. The OLS estimates reveal that workers who receive a bonus earn £2,585 higher in annual labour earnings. The corresponding figure for PRP jobs is approximately $£ 1,868$. As emphasized, the large difference associated with a bonus may reflect unobserved worker characteristics. More able workers are likely to sort into jobs paying bonuses and earn higher compensation of all types. The next column reports fixed effects estimates that seek to control for these characteristics. As expected the bonus premium falls markedly, to $£ 952$ but remains statistically different from zero. The PRP figure falls to $£ 471$ and is now significant at the five percent level instead of the one percent level. 


\section{INSERT TABLE 2}

Ultimately we want to include the pound value of bonuses to examine the extent of substitution but we recognize that it is both common and closer to theoretical derivations to present log earnings equations. We show these in columns 3 and 4 to confirm the same general pattern. The OLS estimation suggests that those receiving bonuses earn 12 percent more than those on times rates while the return to PRP is 6.3 percent. The fixed effect estimates again shrink markedly with those receiving bonuses earning 5 percent more but the return to PRP now insignificantly different from zero. These estimates for the return to receiving a bonus are reasonably close to those estimated in the US. Lemieux et al. (2012) present returns of 8.5 percent in an OLS estimate using the Panel Study of Income Dynamics and 4.1 percent in the associated fixed effect estimate.

As discussed, our bonus receipt indicator fails to capture years where workers are eligible for a bonus but did not meet the requirements for bonus receipt within that year. While we do not have any way of directly observing this from the data, we follow Lemieux et al (2009) in creating a broader measure. From the BHPS we know job changes and we classify a worker as in a bonus job if they ever received a bonus in their current job. Thus, if the original measure fails to capture years on a bonus scheme where there was no payout, this runs the opposite risk of counting years as on a bonus scheme when the scheme was removed. Column five of Table 2 reports fixed effects estimates using this alternative measure of bonus receipt. This reveals a modestly smaller estimate as anticipated but also shows that non-receipt in a given year while eligible does not appear to be generating our estimates.

\section{INSERT TABLE 3}

In Table 3 we present the estimated relationship between bonus amounts and usual earnings. These estimates show the pound to pound conditional relationship between bonus amount and annual earnings. Column 1 presents the OLS estimates demonstrating that for every additional dollar of bonus, the annual earnings are approximately 1.24 pounds larger. Taken at face value, this implies that bonuses and time rate earnings are complements. The estimate holds constant earnings from PRP and implies that annual earnings go up by more than the bonus amount. Specifically time rates go up by approximately 25 percent of the 
bonus amount as well. This would be gravy indeed and might be considered broadly similar to findings in previous studies.

Yet, this fails to account for unmeasured ability that likely causes both bonuses and time rates to be larger as the more able sort into bonus jobs. Column 2 presents the equivalent estimate controlling for worker fixed effects. As expected, this causes the estimated coefficient on the bonus amount to fall markedly. However, it remains positive, statistically significant and of an economically important magnitude. Each pound of bonus is associated with earnings that are 0.6 pounds higher. This suggests clear partial substitution rather than the complementarity suggested by the OLS estimate. Thus, substantially less than the full value of bonuses is observed in total earnings. Each pound of bonus is associated with a 40 pence reduction in time rate earnings. This differs from the flavour of the earlier empirical research that failed to control for worker fixed effects and it suggests that bonuses are not simply gravy added on top.

As a test of nonlinearity in the bonus amount, we include a squared term as shown in the second and third columns of Table 3. These estimates suggest that a non-linearity exists. The rate at which larger bonus amounts are translated into total income is smaller than that for smaller bonus amounts. This result is statistically significant but not in the fixed effect estimate. Nonetheless, the clear pattern in the OLS continues to suggest pure gravy while that

with the fixed effects continues to suggest partial substitution. ${ }^{7}$ We recognize that the variation the variation in Table 3 comes from both sorting into jobs that provide bonuses (the bonus going from zero to positive) and changes in the bonus amount (among positive amounts). This leads to a series of robustness checks.

\section{Robustness Checks}

We undertake a series of robustness checks that assess the source of the identification, the stability of our estimate over a number of subsamples and the influence of functional form and model specification.

First we examine who identifies our fixed effects model and the stability of our key estimate across sources of identification. Specifically, the critical pound value of bonuses can vary and identify the fixed effect estimate in three ways. First, workers can move into bonuses (receiving a bonus in the current period when they did not in the previous period). 
Second, they can move out of bonuses (not receive a bonus in the current period having received a bonus in the previous period). Third, they can remain in bonuses in adjacent periods but experience a change in the amount of receipt (and in income). We separately examine each source of variation and stress that our results tend to be broadly similar for each source of variation. The overall observations associated with each source of variation allow reasonable inference: 4,055 observations moving in, 4,024 moving out and 7,200 changing within. The remaining observations are for those 2,261 workers who never receive a bonus and hence do not contribute to the fixed effects estimate of the bonus amount coefficient. Table 4 shows our fixed effects estimate for those moving in is a 0.39 pound increase in annual earnings for each pound increase in bonus amount. The size is smaller but still positive for those moving out with a 0.27 increase in earnings for each pound increase in bonus amount. Finally, the within estimate is virtually identical to the original estimate at a 0.58 increase in earnings for each pound increase in bonus amount. Each estimate is significantly different from zero. Thus, our general result of a general positive association between bonus and non-bonus earnings that indicates partial substitution is not driven by asymmetries that make only one source of identification meaningful. For instance, there may have simply been increasing bonus receipts in general across our sample period in which nonbonus earnings may also be increasing. This decomposition suggests that such an underlying pattern does not drive the empirical results.

\section{INSERT TABLE 4}

Like all panels, the BHPS suffers attrition, and our focus on workers who may leave employment even if still in the sample makes it more acute. We worried that attrition might be associated with earnings in a way that might lead to a biased estimate of the relationship between bonus and non-bonus earnings. We re-estimated our model on only those workers who we observe at least 10 times and the point estimate was of the same general magnitude (0.552 [s.e. $=0.048])$. A related concern is that one-off bonuses may reflect some idiosyncratic payment rather than the income routinely being at risk. We re-estimated our models including only those workers who received bonus payments at least twice. These estimates were essentially the same as our main estimates $(0.584$ [s.e.=0.018]). In further unreported estimates we continued to increase the number of minimum bonus payments (at least 3 payments, 4 payments etc), and again the estimates did not vary markedly. In sum, 
these estimates suggest that the positive correlation is not driven by any particular pattern of the frequency of bonus receipt.

The bonus to salary relationship may not be stationary across the years for which we have data. To investigate this, we split the sample in half and report the both sets of estimates. There is only modest variation across period: from 0.41 for 1997-2002 and 0.38 for 2003 onwards but both are highly significant. In unreported results we estimate our fixed effects model across a range of different sub-samples of years of the survey; in all cases the coefficient on bonuses remained positive, statistically significant and indicative of substitution. Related to potential changes over time, we also explored using deflated wages only without year dummies, or year dummies using nominal wage values. Neither modification materially changes our results.

We estimated the specification in a series of further sub-samples in an effort to avoid a spurious relationship between bonuses and non-bonus earnings. First, PRP receipt may be problematic as it is incorporated into the derived annual labour income, our dependent variable. We re-estimate our model for workers who do not receive PRP generating a fixed effects estimate of bonus amount of 0.638 [s.e. $=0.023$ ]. Second, bonus receipt and salaries for workers with longer tenure may reflect a variety of factors including deferred compensation. Hence, any trade-off between salaries and bonuses may be more acute early in a job when the compensation scheme reflects a salary - bonus trade-off that is potentially driven more by the external market than by internal labour market negotiations. We re-estimate our OLS model for those workers with less than 2 years of tenure ${ }^{8}$. These reveal a point estimate of 1.201 [s.e. $=0.150$ ] suggesting that our positive bonus coefficient is not being driven by internal labour market institutions such as deferred compensation.

We also recognize that while typical of many in the literature our specification contains a fairly parsimonious set of industry and occupation controls. This could hide occupation and industry variation at a more disaggregated level. We examine this by saturating the model with 77 occupational controls (SOC 2 digit) and 84 industry controls (SIC 2 digit). The resultant fixed effect estimate is essentially unchanged by this degree of detail (0.561 [0.021]). We next re-estimate our model separately for white and blue collar workers. These return surprisingly similar estimates. To focus on the broad group subject to the greatest press scrutiny, we limit the sample to those in the managerial and professional 
occupation groups. This returns only a modestly smaller fixed effect estimate than found for the entire sample (0.544 [.030]).

Perhaps the confounding issue is not the occupation but an effort level of the workers which is unobserved and varies with bonus amounts. While difficult to examine, we undertook several checks with the hours of work measure. We limited ourselves to those who reported working full time. We also added to the control for usual hours a control for usual overtime hours. Neither check produced meaningful differences from the original estimates.

Finally, we were concerned that smaller profit sharing payments or routine Christmas bonuses may be included in our measure. These may be routinely given for reasons other than individual performance and may be causing our estimates to understate the level of substitutability. We re-estimate our results excluding observations where the worker received a bonus but it was less than $£ 1,000$. The fixed effect estimate is 0.579 [s.e. $=0.023$ ].

In summary, despite a variety of robustness tests and specifications, each of our estimates show a positive relationship between bonus levels and earnings but one that suggests substitution between bonuses and time rates. It may be the case that more finely drawn data within a single occupation or with more homogenous workers would reveal different results but we cannot find them with our data. As an attempt to further investigate this, we now consider how this relationship varies across the wage distribution.

\section{Distribution of Bonus Payments}

The bonuses observed at the top of the earnings distribution may be fundamentally different in type from those at the bottom of the distribution. Much of the recent concern with bonuses for bankers has been that they may be able to manipulate a system in which others have imperfect information and, as a consequence, the size of bonuses may have little relationship to true productivity. At the extreme the "performance" measure may have been simply shortterm sales of a "toxic" product. While not passing judgement on this claim, currently the focus of a federal inquiry in the United States, it remains possible that there is more transparency and less ability to manipulate performance measures at the bottom of the earnings distribution than at the top. This could suggest that substitution may be more obvious at the bottom of the distribution. Moreover, as performance pay has been intimately 
tied to growing inequality (Lemieux et al. 2009), there is good reason to explore distributional aspects of substitution.

\section{INSERT TABLE 5}

We first pool the data and run simple quantile regressions. As shown in Table 5, these indicate large coefficients across the distribution but a clear pattern that the positive values increase moving up the distribution. At the bottom of the distribution $(0.10)$ the estimates suggest a pound of bonus is associated with .84 pence of labour earnings. At the top of the distribution, the estimates suggest and enormous 1.9 pounds of earnings associated with every pound of bonus income. ${ }^{9}$ Taken literally this would suggest very strong complements. At the risk of stretching the metaphor, the gravy appears thicker at the top. In unreported estimates, we further extended the estimates out to the $95^{\text {th }}$ and $99^{\text {th }}$ percentile. This follows a similar increasing pattern, 2.418 [0.008] for the $95^{\text {th }}$ percentile and 2.785 [0.019] for the $99^{\text {th }}$ percentile. $^{10}$

Yet, like the earlier estimates, these quantile estimates surely suffer from unmeasured ability influencing the earnings measures. Thus, we implement Koenker's (2004) unconditional fixed effect estimator using the public domain package $\mathrm{R}$ and Koenker's program. The results are shown in the bottom of Table 5 and while much smaller in absolute magnitude, they show the same or even greater percentage growth across the distribution. In the lowest quantile at 0.10 , the coefficient is only .39. There is substantial substitution with workers giving up 61 pence for every pound earned in bonuses. The estimated coefficient steadily increases so that at the top quantile, 0.90 , it is a 0.97 and not statistically different from 1. This says in essence that there is no cost in lost time rates for increased bonus payments at the top of the distribution. Again we explore estimates at the extremes of the distribution. First, we estimate a model with bonus coefficient evaluated at the $5^{\text {th }}$ and $95^{\text {th }}$ percentile. The estimates for these two points are 0.048 [s.e. $=0.061$ ] and 0.934 [s.e. $=0.114$ ], respectively; with the $5^{\text {th }}$ percentile estimate not statistically different from zero. Second, we estimate the $1^{\text {st }}$ and $99^{\text {th }}$ percentile in addition to those points listed in Table 5. This reveals 0.211 [s.e. $=0.118$ ] at the $1^{\text {st }}$ percentile and 1.231 [s.e. $=0.173$ ] at the $99^{\text {th }}$ percentile. These estimates suggest that, once holding unmeasured time invariant ability constant, there is evidence of gravy at the upper most part of the wage distribution but substantial evidence of substitution at the lowest point. 
The critical point from this distributional exercise has been that we typically find evidence of substitution throughout most of the earnings distribution but only after controlling for sorting. The basic implication of the agency model seems supported at all but perhaps the very top of the earnings distribution where the evidence of substitution fades.

\section{CONCLUSION}

The frequent inability of past research to find substitution between performance pay and time rates stood as the starting point for this paper. This is a critical point from a policy perspective as the efficiency of bonus payments rely on a degree of substitution with fixed pay. Indeed, we initially confirmed this finding in simple earnings equations that show higher bonus amounts go together with higher time rate amounts. Yet, such estimates fail to control for the ability sorting that is inherent especially in sorting type models. This led to fixed effect estimates that showed the importance of such sorting and that demonstrated evidence of partial substitution only when accounting for this sorting. This was followed by a series of robustness checks designed to improve the focus of the estimates. We focused only on large bonuses, bonuses that were regular and also focused on the distributional aspects of the estimates. These efforts served to reinforce the early estimates. We found no evidence of complementarity in the fixed effect estimates. Nonetheless, we found strong distributional aspects suggesting that the extent of substitution is very large at the bottom of the earnings distribution and vanishingly small at the top of the earnings distribution. The BHPS data on bonuses payments is imperfect and we readily admit that such a general representative survey of workers may not provide the detail and sample size needed to uncover the implications of a firm deciding to pay such bonuses. Nonetheless, it is striking that our evidence shows partial substitution between base pay and bonuses only when accounting for worker fixed effects and perhaps even more striking that this disappears at the top where bonuses appear to be largely gravy.

There exists room for further testing. First, data sources from other countries that itemize the size of bonuses may be worth investigating. Second, it could also be worth examining other forms of performance pay beyond bonuses and controlling for worker fixed effects. The trade-off between piece rate earnings (or commissions) and fixed wage payments stand as obvious examples but the BHPS does not itemize these earnings. While these other forms of performance pay could inform theoretical models, the current public 
scrutiny is aimed at bonuses. It remains the case that our best efforts to examine bonuses and other earnings have found that they appear to be partial substitutes but only when looking at within worker estimates generated by the fixed effect estimate. 


\section{REFERENCES}

Albanesi, Stefania and Claudia Olivetti. 2008. 'Gender and Dynamic Agency: Theory and Evidence on the Compensation of Top Executives,' Working Paper, Department of Economics, Columbia University.

Azfar, Omar and Stephan Danninger. 2001. 'Profit Sharing, Employment stability and Wage Growth,’ Industrial and Labor Relations Review, 54: 619-630.

Barkume, Anthony J. 2004. 'Using Incentive Pay and Providing Pay Supplements in U.S. Job Markets,' Industrial Relations 43: 618 - 33.

Bebchuk, Lucian, Jesse Fried and David Walker. 2002. 'Managerial Power and Rent Extraction in the Design of Executive Compensation,' University of Chicago Law Review 69: 751-846.

Bell, Brian and John van Reenen. 2010. 'Bankers' Pay and Extreme Wage Inequality in the UK,' Working Paper, Centre for Economic Performance, London School of Economics.

Bell, Brian and John van Reenen. 2013. 'Extreme Wage Inequality: Pay at the Very Top,' American Economic Review 103: 153-157.

Bertrand, Marianne and Sendil Mullainathan, 2001. 'Are CEOs Rewarded for Luck? The Ones without Principals are,' Quarterly Journal of Economics 116: 901-932.

Brick, Ivan, Oded Palmon and John Wald. 2012. 'Too Much Pay-Performance Sensitivity?' Review of Economics and Statistics 94: 276-304.

Brown, Charles. 1992. 'Wage Levels and Method of Pay,' Rand Journal of Economics 23: 366-375.

Cahuc P. and B. Dormont. 1997. 'Profit-sharing: Does it Increase Productivity and Employment?’ Labour Economics 4: 293-319.

Carmichael, H. Lorne and W. Bentley MacLeod. 2000. 'Worker cooperation and the Ratchet Effect,' Journal of Labor Economics 18: 1-19.

Cornelissen, Thomas, John S. Heywood and Uwe Jirjahn. 2011. 'Performance Pay, Risk Attitudes and Job Satisfaction,’ Labour Economics 18: 229-239.

Curme, Michael and Noah Stefanec, N. 2007. 'Worker Quality and Labor Market Sorting,' Economics Letters 96: 202-208.

Dash, Eric. 2010. 'Few Fled Companies Constrained by Pay Limits,' New York Times, March 23: http://www.nytimes.com/2010/03/23/business/23pay.html?ref=bonuses. 
Friebel, Guido and Michael Raith. 2004. 'Abuse of Authority and Hierarchical Communication,’' Rand Journal of Economics 35: 224-244.

Gibons, Robert. 1987. 'Piece-Rate Incentive Schemes,' Journal of Labour Economics 5: 413429.

Green, Colin. P and John S. Heywood. 2008. 'Does Performance Pay increase Job Satisfaction?’ Economica 75: 710-728.

Green, Colin. P and John S. Heywood. 2011. 'Profit Sharing, Separation and Training' British Journal of Industrial Relations, 49: 623-642.

Hart, Robert A. and Olaf Huebler. 1991. 'Are Profit Shares and Wages Substitute or Complementary Forms of Compensation?’ Kyklos 44: 221-231.

Heywood, John S. and Daniel Parent. 2012. 'Performance Pay and the Black-White Wage Gap,' Journal of Labor Economics 2012: 249-290.

Jenkins, Stephen, 2010. 'The British Household Panel Survey and its Income Data’, IZA Discussion Paper No. 5242.

Kaufman, Roger T. 1998. 'The Effects of Gain Sharing on the Basic Wage: The Case of IMPROSHARE,' Labour 12: 595-610.

Koenker, Roger. 2004. 'Quantile Regression for Longitudinal Data,’ Journal of Multivariate Analysis 91: 74-89.

Lazear, Edward P. 2000. 'Performance Pay and Productivity,' American Economic Review 90: $1346-1361$

Laffont, Jean-Jacques. 1990. 'Analysis of Hidden Gaming in a Three-Level Hierarchy,' Journal of Law, Economics, and Organization 6: 301-324.

Lemieux, Thomas, Bentley Macleod and Daniel Parent. 2009. 'Performance Pay and Wage Inequality’ Quarterly Journal of Economics 124: 1-49.

Lemieux, Thomas, Bentley Macleod and Daniel Parent. 2012. 'Contract Form, Wage Flexibility and Employment,' American Economic Review, 102: 526-531

MacLeod, W. Bentley. 2003. 'Optimal Contracting with Subjective Evaluation,' American Economic Review 93: 216-240.

Mitchell, Daniel J.B., David Lewin and Edward E. Lawler. 1990. 'Alternative Pay Systems, Firm Performance and Productivity,' in ed. Alan S. Blinder, Paying for Productivity: A Look at the Evidence, Washington DC: The Brookings Institution Press.

Parent, Daniel. 1999. 'Methods of Pay and Earnings: A Longitudinal Analysis,' Industrial and Labor Relations Review 53: 71-86. 
Prendergast, Canice and Robert Topel. 1993. 'Discretion and Bias in Performance Evaluation,’ European Economic Review 37: 355-365.

OECD. 2011. 'Divided We Stand: Why inequality Keeps Rising', Paris: OECD Publishing.

Shearer, Bruce. 2004. 'Piece rates, fixed wages and incentives: Evidence from a field experiment'. The Review of Economic Studies, 71:513-534.

Stewart, Mark. 2011. 'The Changing Picture of Earnings Inequality in Britain and the Role of Regional and Sectoral Differences,' National Institute Economic Review, 218: R20-R32. Wadhwani S. And M. Wall. 1990. 'The Effects of Profit Sharing on Employment, Wages Stock Returns and Productivity,' The Economic Journal 100: 1 -17.

Weitzman, M. (1984). The Share Economy. Cambridge, MA: Harvard University Press. Zaharieva, Anna. 2010. 'Risk Sharing and Employee Motivation in Competitive Search Equilibrium,’ Working Paper, Department of Economics, University of Konstanz, Konstanz, Germany. 
TABLE 1 Summary Statistics, Male Private Sector Employees, 1997-2008

\begin{tabular}{lcc}
\hline & Bonus & No Bonus \\
\hline Annual Labour Income & $27,031.20$ & $21,327.24$ \\
Bonus Amount & $3,180.37$ & \\
Performance Pay & 0.278 & 0.091 \\
Normal Hours & 39.977 & 39.985 \\
Age & 40.069 & 41.693 \\
A Level & 0.263 & 0.222 \\
Diploma & 0.099 & 0.089 \\
Degree or Higher & 0.198 & 0.128 \\
Union & 0.232 & 0.219 \\
Temporary Job & 0.006 & 0.034 \\
Large Firm & 0.473 & 0.387 \\
Manager/Supervisory Duties & 0.593 & 0.393 \\
Observations & 9,482 & 12,376 \\
\hline
\end{tabular}

Source: BHPS 
TABLE 2 Bonus Receipt Wage Premium on (non-bonus) Annual Incomes (£2005), Male Private Sector Employees, 1997-2008.

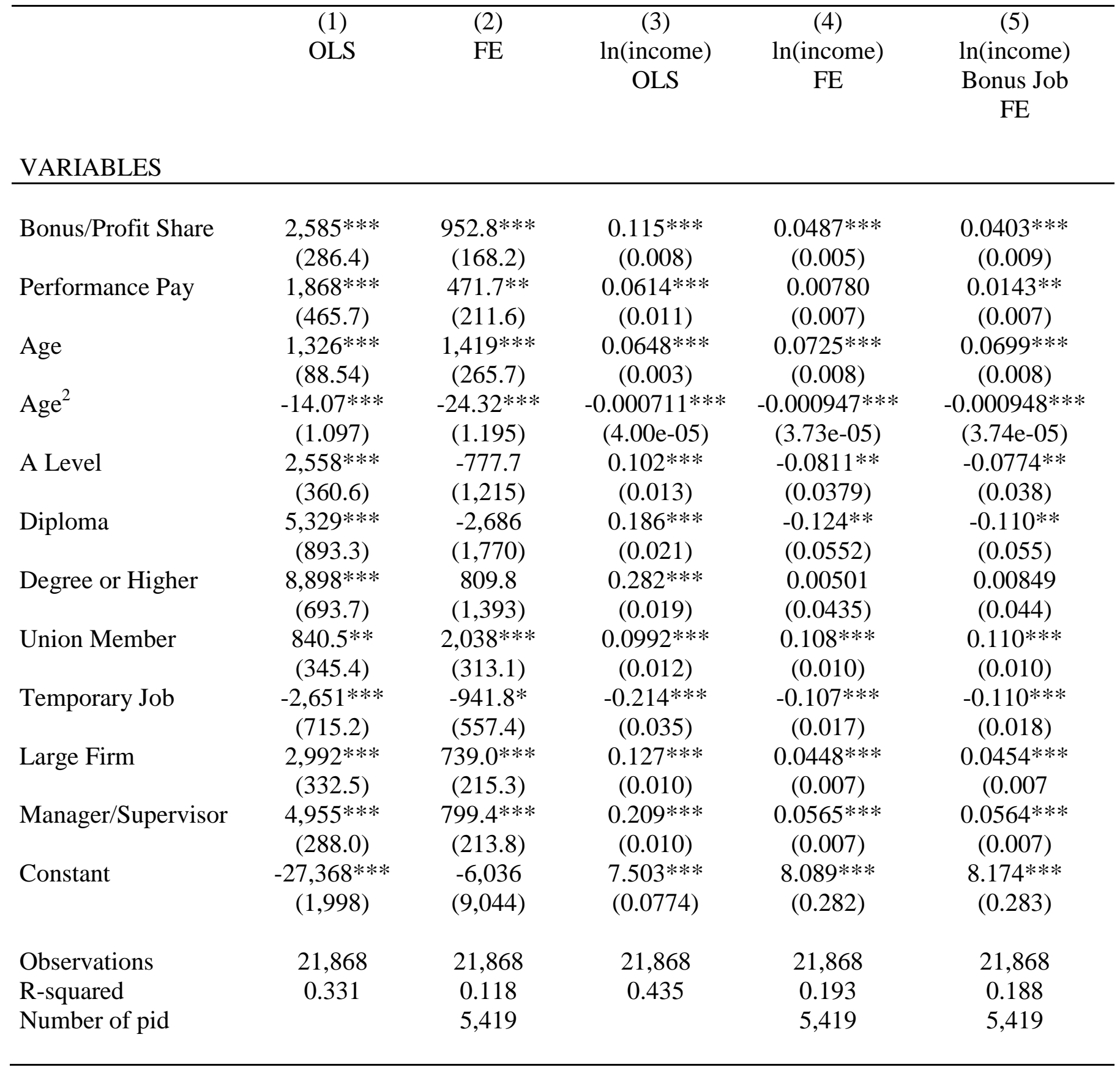

Source: BHPS. Robust standard errors in parentheses. ${ }^{*}, * *$ and $* * *$ indicate statistical significance at the $10 \%, 5 \%$ and $1 \%$ respectively. Controls included but not reported are hours worked, occupation, industry, region and year dummies. 
TABLE 3: Bonus Amount and Non-Bonus Labour Income, Male Private Sector Employees, 1997-2008

\begin{tabular}{lcccc}
\hline & OLS & OLS & FE & FE \\
& $(\mathrm{I})$ & $(\mathrm{II})$ & & $(\mathrm{II})$ \\
\hline & & & & \\
Bonus Amount(£2005) & $1.170^{* * *}$ & $\begin{array}{c}1.470^{* * *} \\
(0.106)\end{array}$ & $0.580^{* * *}$ & $0.583^{* * *}$ \\
& $(0.0613)$ & $(0.0209)$ & $(0.036)$ \\
Bonus Amount $^{2}$ & & $-5.4 \mathrm{e}^{-06 * * *}$ & & $-3.36 \mathrm{e}^{-08}$ \\
& & $\left(1.3 \mathrm{e}^{-06}\right)$ & & $\left(4.9 \mathrm{e}^{-07}\right)$ \\
Performance Pay & $1,182^{* * *}$ & $951.353^{* *}$ & $412.8 * *$ & $378.837^{*}$ \\
& $(396.6)$ & $(409.6)$ & $(208.1)$ & $(210.1)$ \\
Constant & $-23,055^{* * *}$ & $-22,757.07^{* * *}$ & $-1,994.00$ & $-4,912.14$ \\
& $(1,744)$ & $(1,740)$ & $(8,953)$ & $(8969.59)$ \\
Observations & & & & \\
R-squared & 21,868 & 21,868 & 21,868 & 21,868 \\
Number of pid & 0.419 & 0.425 & 0.153 & 0.158 \\
\hline
\end{tabular}

Source: BHPS. Standard errors in parentheses and clustered by worker in the OLS. *,** and *** indicate statistical significance at the $10 \%, 5 \%$ and $1 \%$ respectively. All other controls as per Table 2 . 
TABLE 4: Sub Sample Estimates: Bonus Amount and Non-Bonus Labour Income, Male Private Sector Employees, 1997-2008

\begin{tabular}{lccccc}
\hline & $\begin{array}{c}(1) \\
\text { moved into } \\
\text { bonus } \\
\text { payment }\end{array}$ & $\begin{array}{c}(2) \\
\text { moved out } \\
\text { of bonus } \\
\text { payment }\end{array}$ & $\begin{array}{c}(3) \\
\text { moved within } \\
\text { bonus payment }\end{array}$ & $\begin{array}{c}(4) \\
1997-2002\end{array}$ & $\begin{array}{c}\text { (5) } \\
\text { (2003-2008 }\end{array}$ \\
\hline Bonus Amount(£2005) & $0.388^{* * *}$ & $0.271^{* * *}$ & $0.583^{* * *}$ & $0.408^{* * *}$ & $0.379 * * *$ \\
& $(0.0445)$ & $(0.0549)$ & $(0.0209)$ & $(0.0468)$ & $(0.0214)$ \\
Performance Pay & $-968.2^{* * *}$ & $916.7 *$ & -141.3 & $764.1 * *$ & 6.712 \\
Constant & $(359.8)$ & $(517.4)$ & $(253.2)$ & $(334.9)$ & $(229.7)$ \\
& $-26,394$ & 24,275 & $-6,942$ & 6,343 & $-12,160$ \\
Observations & $(18,158)$ & $(25,686)$ & $(12,673)$ & $(15,476)$ & $(12,561)$ \\
R-squared & & & & & 1,247 \\
Number of pid & 4,055 & 4,024 & 7,250 & 10,621 & 11,247 \\
\hline
\end{tabular}

Source: BHPS. Standard errors in parentheses. *,** and *** indicate statistical significance at the $10 \%, 5 \%$ and $1 \%$ respectively. All other controls as per Table 2. 
TABLE 5, Quantile Regression Estimates: Male Private Sector Employees, 1997-2008

\begin{tabular}{lccccc}
\hline & $(1)$ & $(2)$ & $(3)$ & $(4)$ & $(5)$ \\
VARIABLES & $10 \%$ & $25 \%$ & median & $75 \%$ & $90 \%$ \\
\hline \multirow{2}{*}{ Bonus Amount(£2005) } & $0.848^{* * *}$ & $0.973^{* * *}$ & $1.217^{* * *}$ & $1.533^{* * *}$ & $1.919^{* * *}$ \\
& $(0.0277)$ & $(0.0414)$ & $(0.0520)$ & $(0.0506)$ & $(0.0968)$ \\
Performance Pay & $714.8^{* * *}$ & $832.3^{* * *}$ & $970.0^{* * *}$ & $868.3^{* * *}$ & 353.1 \\
& $(161.7)$ & $(139.1)$ & $(189.4)$ & $(224.8)$ & $(349.4)$ \\
Observations & & & & & \\
& 21,868 & & & & \\
\hline
\end{tabular}

\begin{tabular}{|c|c|c|c|c|c|}
\hline \multicolumn{6}{|c|}{ Quantile Fixed Effects } \\
\hline & $10 \%$ & $25 \%$ & median & $75 \%$ & $90 \%$ \\
\hline Bonus Amount(£2005) & $\begin{array}{c}0.386 * * * \\
(0.036)\end{array}$ & $\begin{array}{c}0.479 * * * \\
(0.047)\end{array}$ & $\begin{array}{c}0.605 * * * \\
(0.046)\end{array}$ & $\begin{array}{c}0.765 * * * \\
(0.071)\end{array}$ & $\begin{array}{c}0.966 * * * \\
(0.060)\end{array}$ \\
\hline Performance Pay & $\begin{array}{c}167.147 \\
(222.843)\end{array}$ & $\begin{array}{c}115.703 \\
(0.00)\end{array}$ & $\begin{array}{c}297.511^{* * *} \\
(95.814)\end{array}$ & $\begin{array}{c}329.916 * * * \\
(131.541)\end{array}$ & $\begin{array}{c}358.292 * * * \\
(191.385)\end{array}$ \\
\hline Observations & 21,868 & & & & \\
\hline
\end{tabular}

Source: BHPS. Standard errors in parentheses. *,** and *** indicate statistical significance at the $10 \%, 5 \%$ and $1 \%$ respectively. All other controls as per Table 2. 
TABLE A1 Variation in Annual Income, Bonus Payment and Receipt, 1997-2008, Male Private Sector Employees.

\begin{tabular}{lll}
\hline & Annual Income & Annual Bonus \\
\hline Mean & $23,985.30$ & $1,408.65$ \\
Between Individual Std.Dev & $12,755.52$ & $6,061.33$ \\
Within Individual Std.Dev & $7,807.61$ & $6,447.08$ \\
& \multicolumn{2}{c}{ Bonus Receipt } \\
& \multicolumn{2}{c}{} \\
\# Changes in Bonus Receipt & 6,843 & \\
\# Never Received Bonus & 2,261 & \\
& & \\
\hline
\end{tabular}

Source: BHPS. 
Figure 1, Average Bonus Payments UK 1997-2008, Male Private Sector Employees, BHPS.

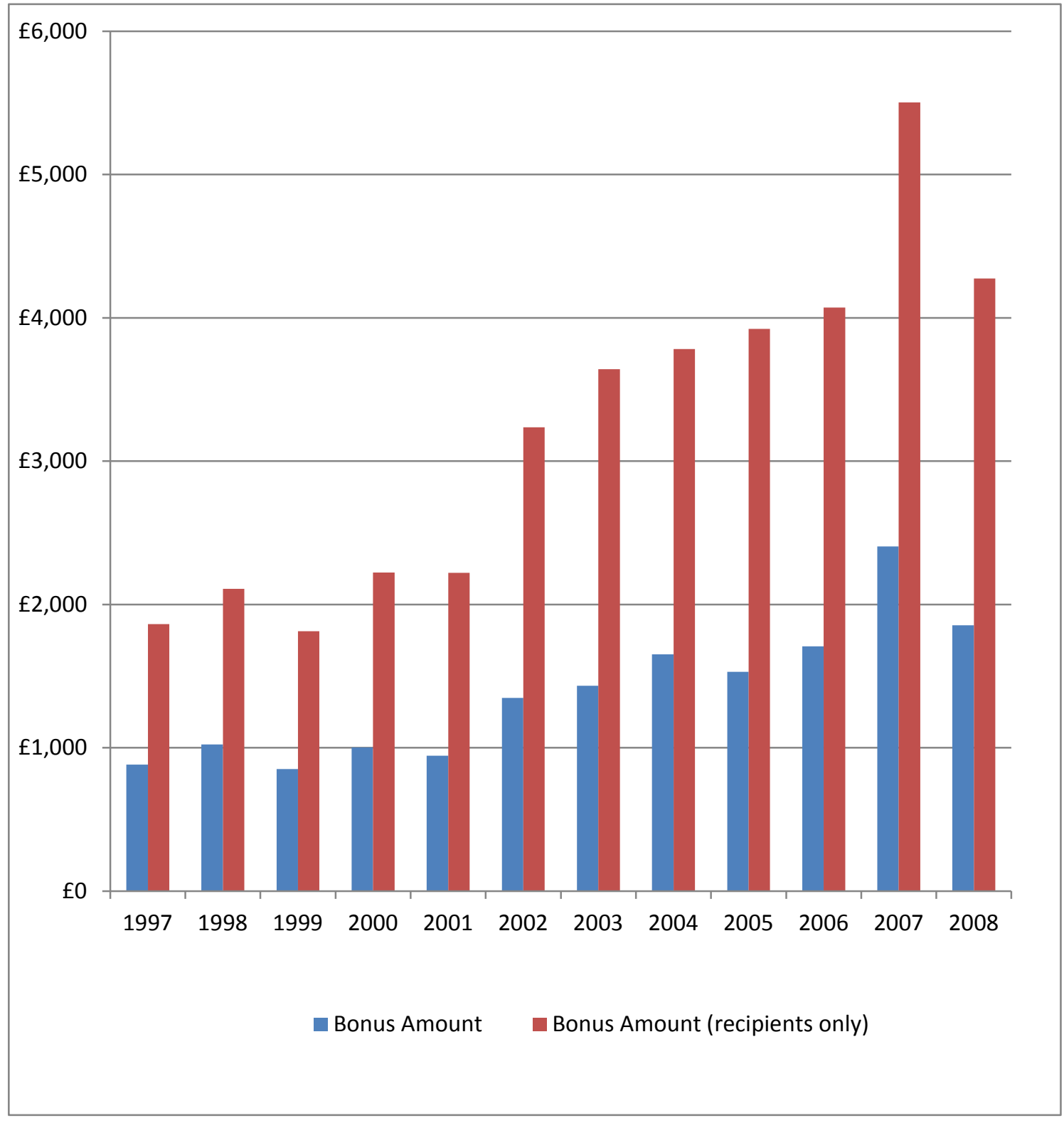


FIGURE 2 Annual Incomes, Bonus versus non-Bonus recipients, 1997-2008, Male Private Sector Employees, BHPS.

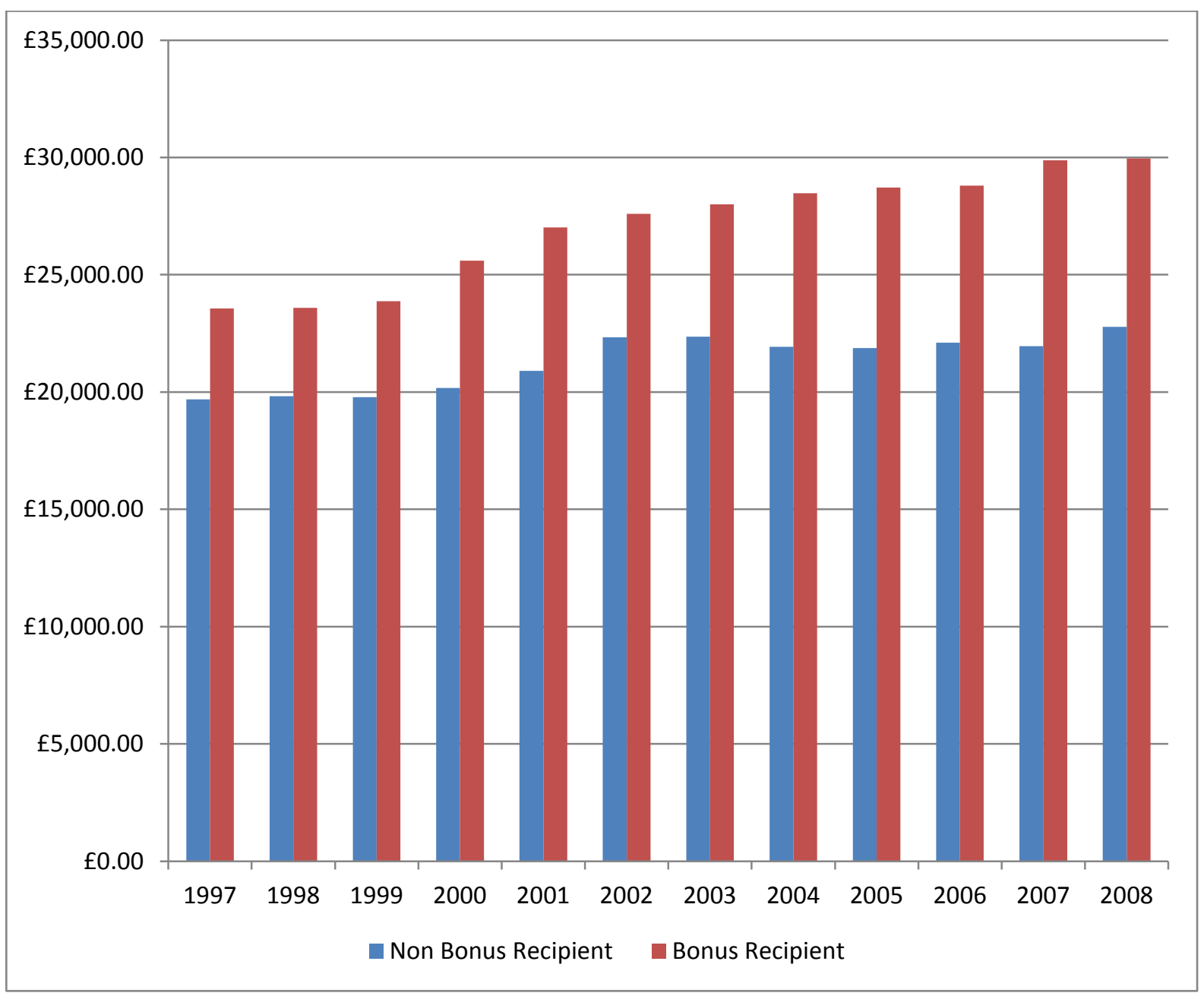


Figure 3a, Bonus Share of Total Annual Income across Income Distribution, 1997-2008, Male Private Sector Employees, Bonus Receivers Only, BHPS.

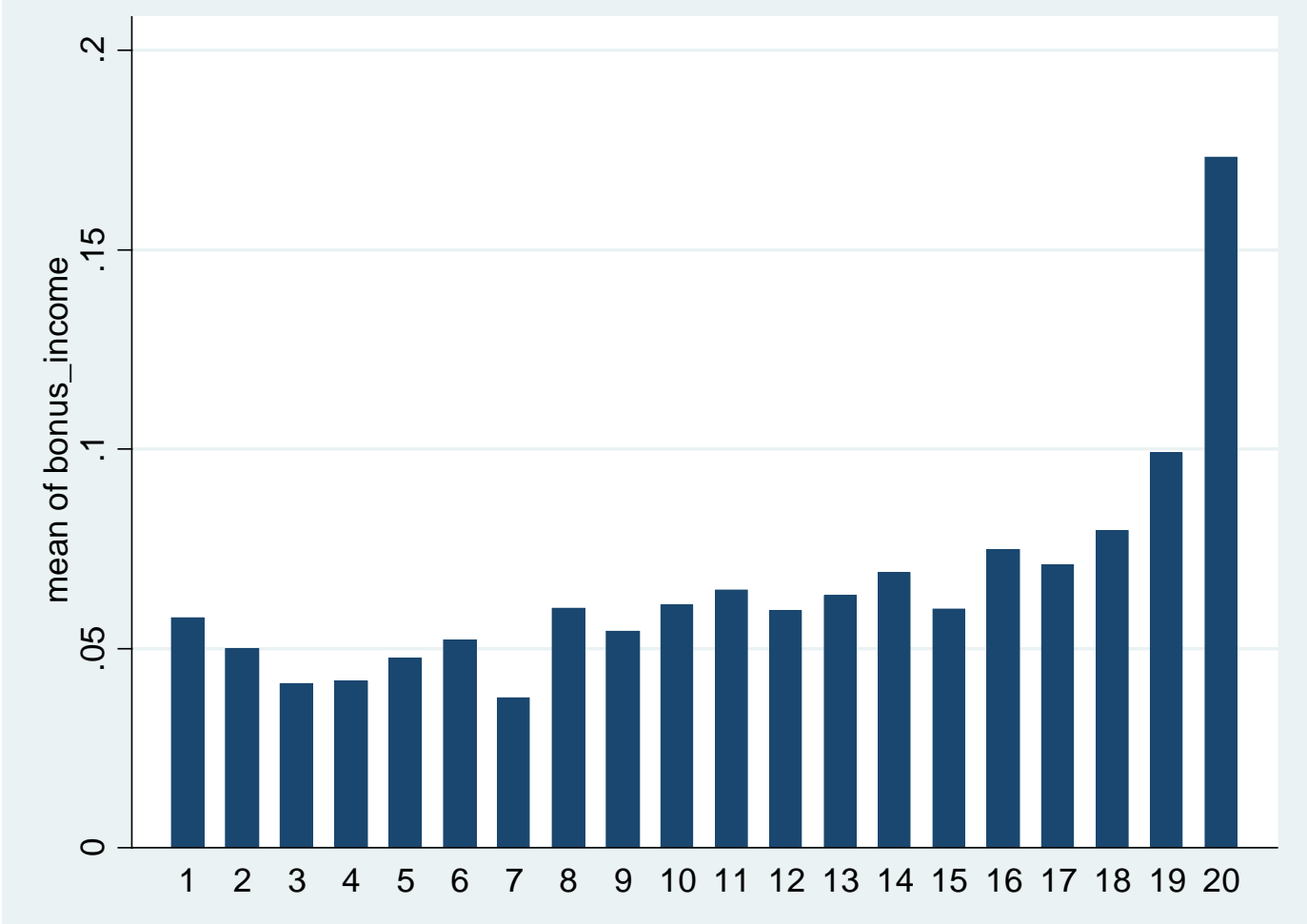


Figure 3b, Bonus Share of Total Annual Income across Income Distribution, Top Decile, 1998-2008, Male Private Sector Employees, Bonus Receivers only, BHPS.

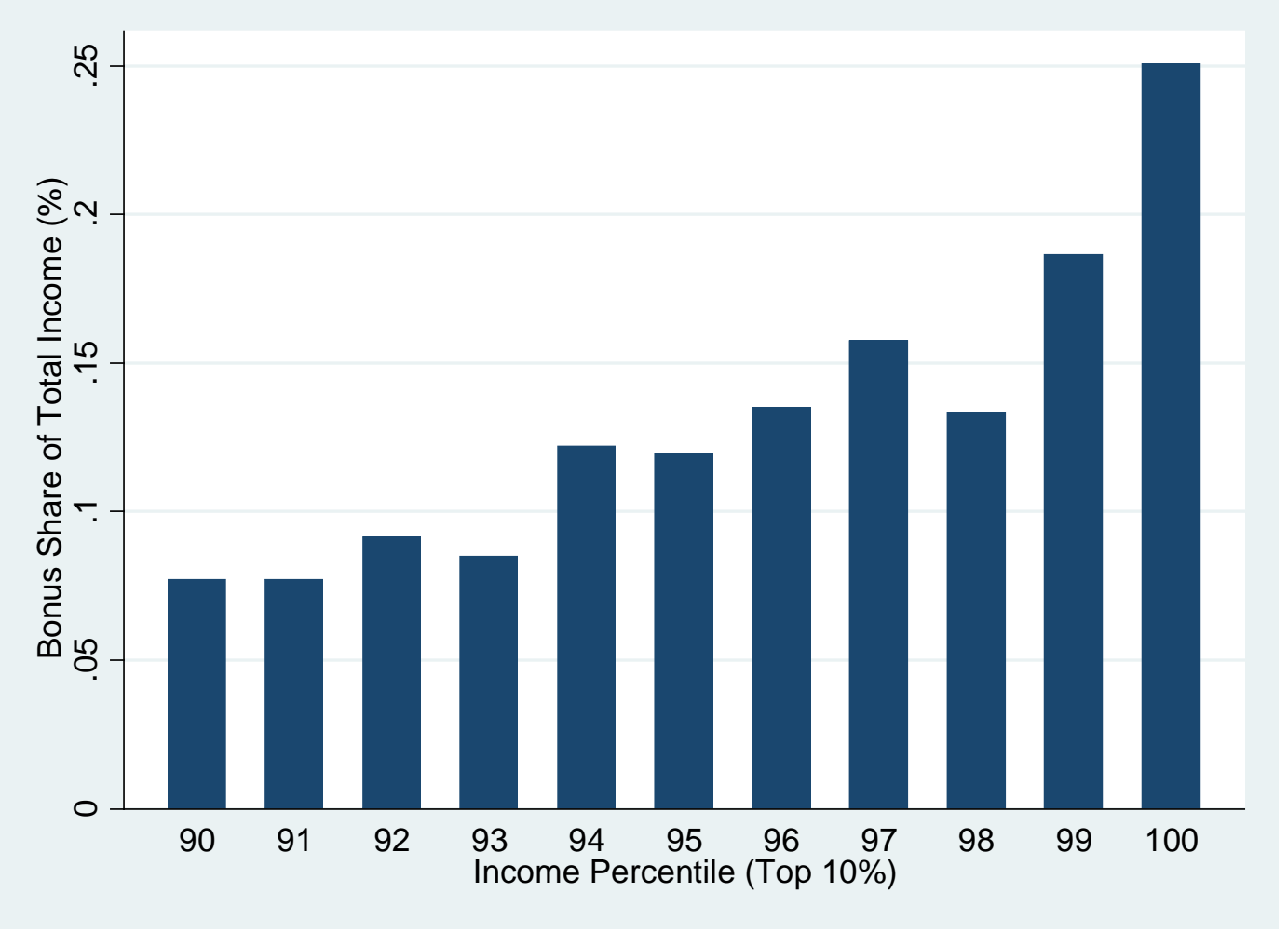




\title{
Endnotes
}

\begin{abstract}
${ }^{1}$ Among numerous illustrations, we highlight two in the New York Times, "Banks Prepare for Big Bonuses, and Public Wrath” (9 ${ }^{\text {th }}$ Jan 2010) and “A Modest Proposal to End Those Outlandish Bonuses” (16 ${ }^{\text {th }}$ Sep 2009) and two in The Times, "No More Money for Nothing” (25 $5^{\text {th }}$ Jan 2009) and “Bonus Culture Thrives with Payouts of $£ 22 b n$ ” (27 $7^{\text {th }}$ May 2011).
\end{abstract}

${ }^{2}$ Lemeuix et al. (2012) use the PSID to estimate the influence of a dichotomous bonus receipt indicator on an earnings variable that likely includes the value of bonuses. They find a small positive influence. When they include as an alternative a dichotomous indicator of whether the current job has ever paid a bonus, they find no effect. While not in the precise spirit of those estimating the extent of substitution, these results do appear consistent with substantial substitution.

${ }^{3}$ It is important to note that just because bonuses may be based on objective indicators does not mean they reflect market forces. As a potential illustration, despite fear among large US banks to the contrary, government interventions restricting pay and bonuses apparently did not result in an exodus of talent (Dash 2010).

${ }^{4}$ Indeed, both Prendergast and Topel (1993) and Laffont (1990) argue that collusion and hidden gaming within the hierarchy between superiors and subordinates becomes more likely when the superiors are paid in fashions other than simply being residual claimants of their subordinate's output. Surely, bonuses run this risk.

${ }^{5}$ Please refer to Jenkins (2010) for a summary of this information.

${ }^{6}$ The one key difference that they note is that the BHPS appears to under-sample high earners while in ASHE response is effectively mandatory. However, we do not use the ASHE data as it lacks a specific measure of bonuses.

${ }^{7}$ As mentioned, we see the log-log specification as problematic especially in the fixed-effect estimate because of the large number of zero values for the bonus amount. If we arbitrarily set the log of zero to zero itself and estimate a log-log specification in the OLS we return an estimate of 0.043 [s.e=0.008]). 
${ }^{8}$ Fixed effects estimation of wages do not make sense in a situation where we are essentially limiting our sample to new hires.

${ }^{9}$ In estimates available upon request, we added the squared bonus amount in the quantile estimates. The coefficient is routinely negative but does not dominate the linear term when evaluated at quantile bonus amount. The pattern continues to show increases net coefficients when moving up the distribution.

${ }^{10}$ In additional estimates available upon request we re-estimated our model of the returns to bonus receipt in a quantile regression setting. These revealed increasing returns to bonus receipt from $£ 1,647$ at the $10^{\text {th }}$ percentile to $£ 2,329$ at the $90^{\text {th }}$ percentile. 